\title{
The mechanical performance analysis of double-layered high-strength stirrup confined concrete columns of different cross-section
}

\author{
Xiurong Yang ${ }^{1, a}$, Cheng Fan ${ }^{2, b, *}$ \\ ${ }^{1}$ Department of Civil Engineering, Dalian University, Dalian, 116622, China \\ ${ }^{2}$ Department of Civil Engineering, Dalian University, Dalian, 116622, China \\ ayangxiurong6@163.com, b249592174@qq.com
}

Keywords: Double Stirrups; Mechanical Behaviors; ABAQUS; Effect Factors;

\begin{abstract}
In order to study the mechanical performance analysis of double-layered high-strength stirrup confined concrete columns of different cross-section, using ABAQUS of finite element software for numerical simulation and experimentally comparison methods to analyze different stirrup characteristic value, strength of stirrup and stirrup spacing factor on confined effectiveness of double-layered high-strength spiral stirrup confined circular and square concrete columns, the author validated the higher compression bearing capacity and better ductility of double-layered high-strength spiral stirrup confined circular concrete columns.
\end{abstract}

\section{Introduction}

With the development of high-rise building and super high-rise building in recent years, requirements for the compression of reinforced concrete column in the high-rise building with greater carrying capacity, larger bearing section and higher seismic performance, including the underlying pillars of bearing capacity is higher and higher, increasing the diameter of the pillar. So fat beam and column [1] becomes an intractable problem in engineering, not only occupies space, but also wasted materials. Although the concrete easy to be obtained and it's highly skilled, high compressive strength, brittleness, ductility and anti-seismic capability are weak. In order to improve the ultimate bearing capacity and energy dissipation capacity of concrete columns, put forward double-layered high-strength stirrup confined concrete columns. Its concrete component composed of two layers of longitudinal reinforcement and stirrup reinforcement cage, adopting double stirrup constraint, not only can reduce the pillar's cross section area of the tall buildings and high-rise buildings, but also can improve the bearing capacity, ductility and seismic performance.

The paper will combine to the steel-concrete filled steel tube [2], concrete filled steel tube rectangular column [3], composited high-strong stirrup confined concrete column [4], with ABAQUS of the finite element software to numerical analysis the different cross-section of double-layered high-strength stirrup confined concrete columns, and verified the higher pressure bearing capacity and better ductility of double-layered high-strength stirrup confined circular concrete columns.

\section{Three-Dimensional Finite Element Model}

The constitutive relation of constraint concrete in high-strength stirrup confined high-strength concrete columns is the important basis of nonlinear analysis. In this paper, using the constitutive model of the stress and the strain in confined concrete is provided by the literature [5], based on the experiment in literature [6]. It's easy to contrastive analysis and the same other date, when modeling analysis of square column compared with circular column. Only change the shape of the component to square, the square outer spiral stirrups is instead of circular stirrup. Meshing of different parts of circular concrete columns are shown in Figure 1, ones of square columns are shown in Figure 2. 

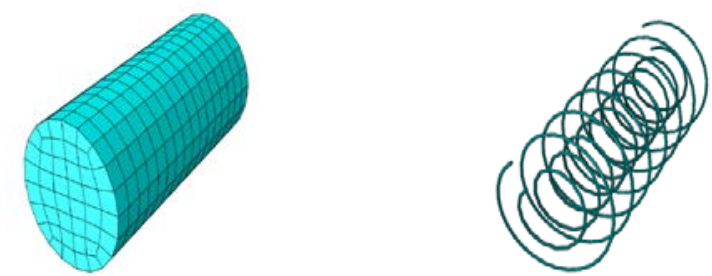

Fig.1 Meshing of different parts of circular columns
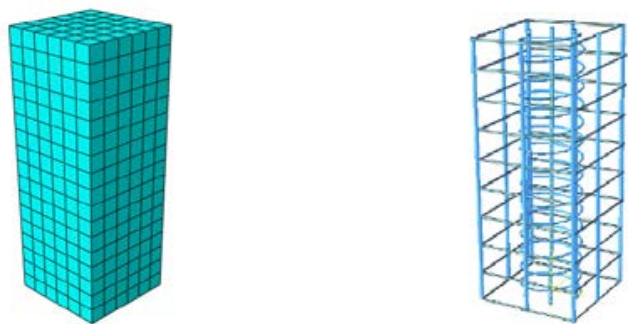

Fig.2 Meshing of different parts of square columns

In order to verify the accuracy of the numerical simulation results, the ABAQUS is used to simulate double-layered high-strength stirrup confined concrete columns of different cross-section loading process of the stress-strain curve. It is shown in figure 3.Based on trials in the literature [6], calculated value compared with experimental value is shown in table 1.

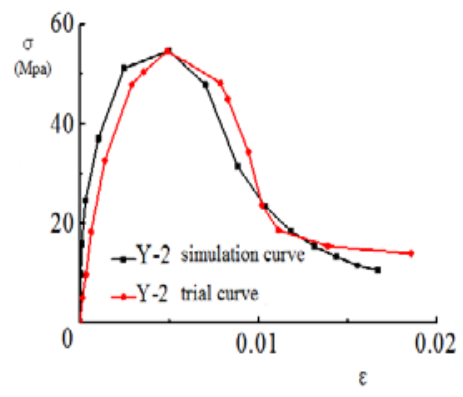

(a)Y-1

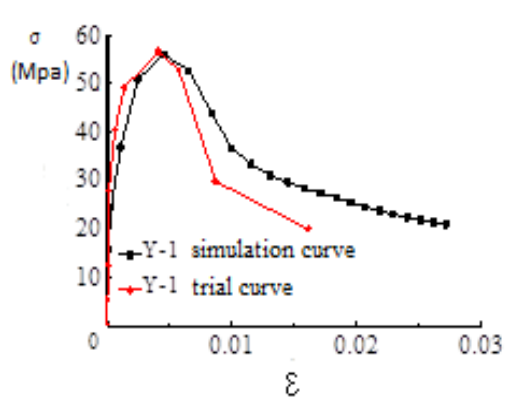

(b)Y-2

Fig.3 Comparison of experimental results and calculated on $\varepsilon$ - $\sigma$ curves

Tab.1 Comparision of experimental and calculated results

\begin{tabular}{ccccc}
\hline No. & $\sigma / \varepsilon$ & trial value & calculated value & trial value / calculated value \\
\hline Y-1 & $\varepsilon$ & 0.00437 & 0.0046 & 0.950 \\
Y-1 & $\sigma /(\mathrm{MPa})$ & 56.68 & 56.0625 & 1.011 \\
Y-2 & $\varepsilon$ & 0.0049 & 0.00496 & 0.987 \\
Y-2 & $\sigma /(\mathrm{MPa})$ & 54.55 & 56.645 & 0.998 \\
\hline
\end{tabular}

From figure 3 and table 1, higher compression is shown between bearing capacity and better ductility of double-layered high-strength stirrup confined concrete columns of different cross-section, and the numerical simulation results coincides well with experimental data.

\section{Contrastive Analysis Mechanics Properties of Square and Circular Column}

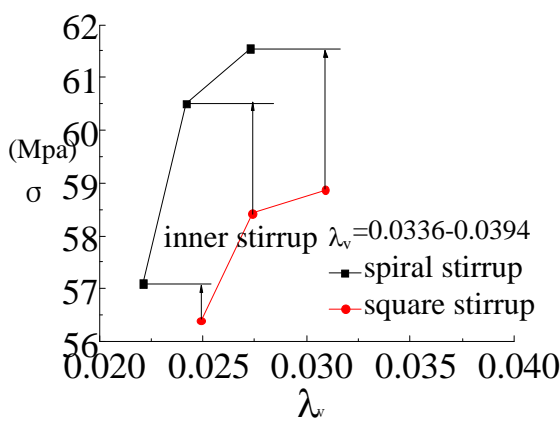

(a) $\lambda_{v}=0.0336-0.0394$

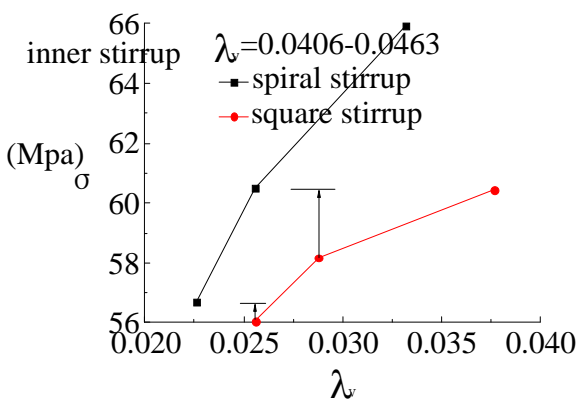

(b) $\lambda_{v}=0.0406-0.0463$

Fig.4 Comparison with the strength influence of square and cylinder column on outer stirrup characteristic value 
From the figure 4, with the increase of the outer stirrup characteristic value, the range of the increased capacity in the circular column outer spiral stirrups will be bigger and bigger.

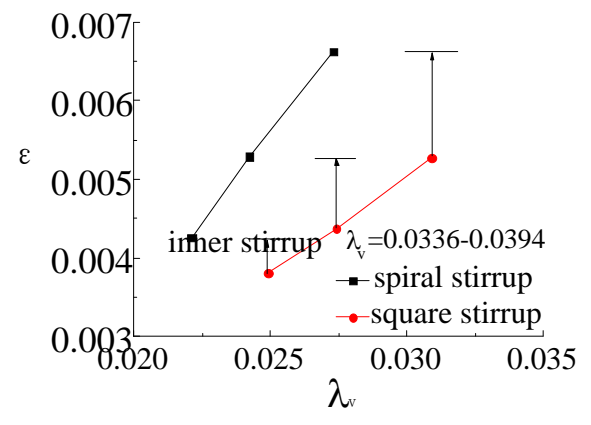

(a) strength influence

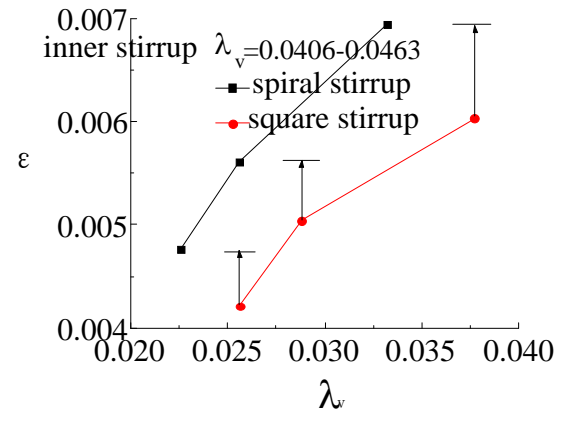

(b) ductility influence

Fig.5 Comparison with the ductility influence of square and cylinder column on outer stirrup characteristic value

From the figure 5, with the increase of the outer stirrup characteristic value, the improved ductility performance of circular column will be more and more obvious.

\section{Contrastive Analysis of Stirrup Yield Strength}

The stirrup spacing are $30 \mathrm{~mm}$. Inside and outside stirrup yield strength is $436 \mathrm{Mpa}$. The outer stirrup yield strength is $436 \mathrm{Mpa}, 721 \mathrm{Mpa}$ and $1128 \mathrm{Mpa}$. Then, contrastive analysis betwee the simulation results of three groups data is shown in fig 6 .

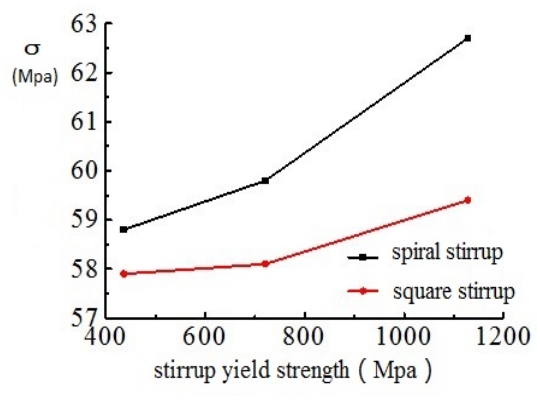

(a) strength influence

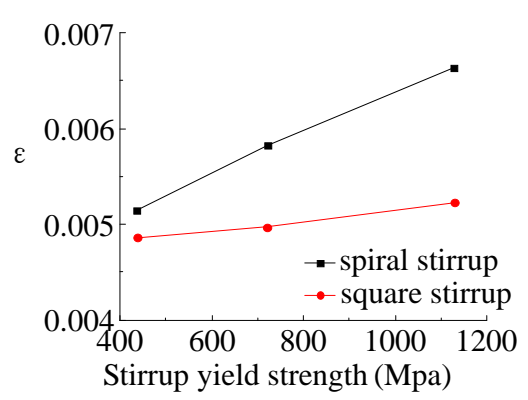

(b) ductility influence

Fig.6 Comparison with the strength and ductility influence of square and cylinder column on outer stirrup characteristic value

In the figure 6, compared with the double-layered high-strength stirrup confined square concrete columns, the increase of the outer stirrup yield strength, the bearing capacity and ductility of circular concrete column performance improvement degree are bigger and bigger.

\section{Contrastive Analysis of Stirrup Spacing}

In the literature [8], after selecting three groups of circular column specimens Y-1, Y-8, Y-15, with the change of outer stirrup spacing, the change of ultimate strength and ultimate strain of six groups specimens can be observed.
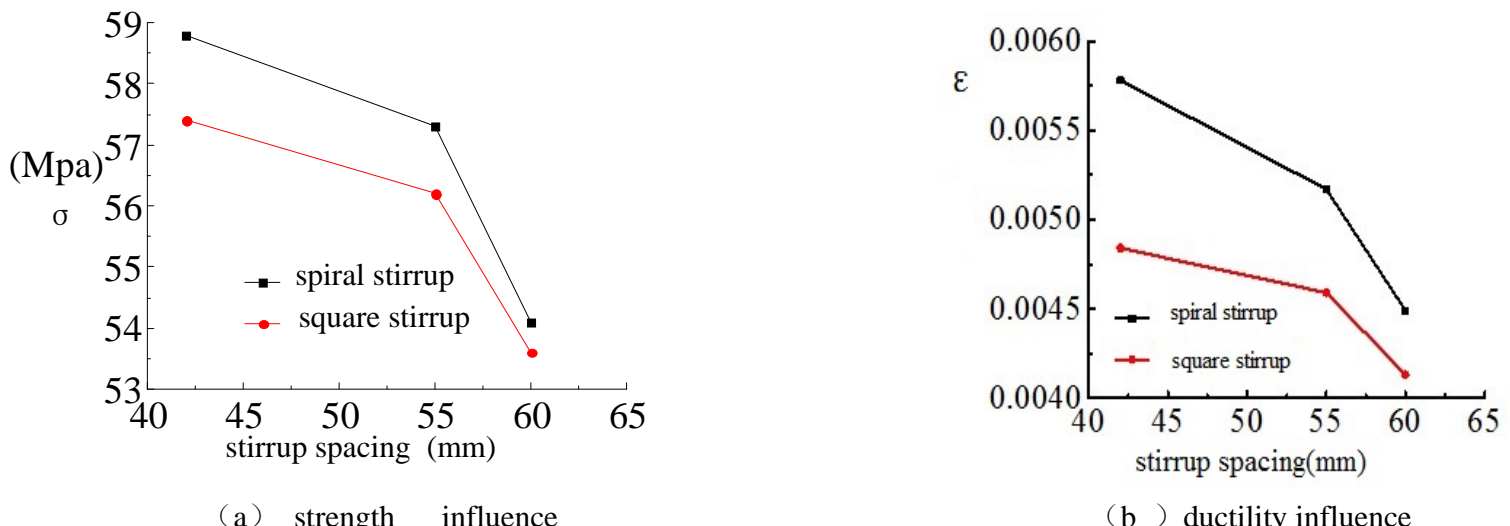

(b ) ductility influence

Fig.7 Comparison with the strength and ductility influence of square and cylinder column on outer stirrup spacing 
The figure 7 shows that with the increase of the stirrup spacing, double-layered stirrup confined concrete bearing capacity and ductility of circular column and square column are improved and concrete circular columns constraint effect is better.

\section{Conclusion}

with ABAQUS of the finite element software, numerically analysis the different cross-section of double-layered high-strength stirrup confined concrete columns, verified the higher pressure bearing capacity and better ductility of double-layered high-strength stirrup confined circular concrete columns. By analyzing the different stirrup characteristic value, the stirrup spacing and the stirrup strength factor on double-layered high-strength stirrup confined concrete circular columns to verify the double high strength spiral stirrups of high strength concrete circular columns constraints is better.

\section{Acknowledgement}

The author would like to thank the financial support by the Liaoning Leading Academic Discipline Project of Liaoning Provincial Education Commission. Fan Cheng (1976-), male, the Dalian city of Liaoning Province, university professor, Doctor of Engineering.

\section{References}

[1] Hanxiong Lin. Analyses the construction technology and quality control of architectural steel structure[J]. China Homes,2011.197-199.

[2] Sun Wang, Ping Li. Numerical simulation of steel reinforced concrete column failure process[J]. Journal of Chongqing Jiaotong University: Nature Science,2009.1052-1055.

[3] Guohuang Yao, Suwen Sun, Xiuming Li. Study on the mechanical properties of axial compression steel-concrete-filled steel tube column[J]. Progress in Steel Building Structures,2009.26-33.

[4] Kun Yang, Qingxuan Shi. Finite element analysis of axially loaded concrete square columns confined by high-strength lateral ties[J]. Journal of Xi'an University of Architecture \& Technology: Natural Science Edition,2009.161-168.

[5]Jianjing Jiang. Reinforced Concrete Structure[M]. China Building Industry Press, Beijing, 1998

[6] Zhanzhan Zheng. Theoretical derivation and numerical simulation of vertical bearing capacity about double stirrup constraint concrete circular column[D]. Master Dissertation of Jiangxi University of Science and Technology,2012.1-60. 